MATEC Web of Conferences 10, 05001 (2014)

DOI: $10.1051 /$ matecconf/ 20141005001

(C) Owned by the authors, published by EDP Sciences, 2014

\title{
Investigation into Common Decay of Educational Buildings in Malaysia
}

\author{
S.W. $\operatorname{Tan}^{1}$, M.A. Othuman Mydin ${ }^{2, \text { a }}$, N. Md Sani ${ }^{3}$, M.Z. Sulieman ${ }^{4}$ \\ ${ }^{1,2,3,4}$ School of Housing, Building and Planning, Universiti Sains Malaysia, 11800 Penang, Malaysia
}

\begin{abstract}
All types of buildings will undergo decay and deterioration over a period of time. In the past few years, there have been numerous official reports in the mass media relating to building decay and failures throughout the country. Building decay and failures are becoming ordinary phenomena in the construction industry. This study is firstly intended to identify and differentiate the common building decay and failures faced by Malaysian educational buildings. Seven educational buildings in Kedah were selected as case studies. Inspections were conducted and the decay of the respective buildings was recorded. The persons in charge of the educational buildings were also interviewed and the results were used for this study as well.
\end{abstract}

\section{Introduction}

Decay and failures commonly occur to the components of educational buildings such as the roofs, walls, floors, ceilings, toilets, doors and windows [1]. Ong [2] indicated that building decay becomes a critical issue only if it is major or excessive. The government has allocated a considerable sum of money towards rectifying decay and failures found in educational buildings [3]. These decay and failures may cause unexpected accidents and even death. For example, on $12^{\text {th }}$ September 2005, a teacher fell to his death when a decayed plywood floor of a two-storey educational building block in SJK (C) Keat Hwa, Kedah gave way. It is believed that the floor was infested with termites [4]. The physical aspects of an educational building environment can have an effect on the teaching and learning, to either help or inhibit the process [5,6]. From the cases that have been reported, it can be concluded that decay and failures are fatal and critical because they are harmful to the users and the building itself, causing damage, serious injuries and death $[7,8,9]$. Buildings are designed as structural systems, and consequently, when a major component of the building fails, it can trigger a series of failures $[10,11,12]$. This paper will identify and differentiate the common decay and deterioration faced by educational buildings.

\section{Site Selections}

Seven educational buildings were chosen as case studies. The selected educational buildings were the Sekolah Menengah Kebangsaan Aman Jaya, Sekolah Jenis Kebangsaan (C) Chung Hwa, Sekolah Menengah Kebangsaan Tunku Ismail, Sekolah Kebangsaan Taman Seri Wang, Sekolah Kebangsaan Seri Gedong, Sekolah Menengah (Persendirian) Sin Min and Sekolah Menengah Kebangsaan Gurun.

\footnotetext{
${ }^{a}$ Corresponding author: azree@usm.my
} 
After obtaining the approval of the educational building authorities, the inspection work was carried out. It was important to conduct site visits to the educational buildings in order to identify the current condition of the selected educational buildings.

\section{Results and Discussions}

Seven educational buildings in Kedah were selected as case studies. All the data were collected through visual inspections and interview sessions with the person in charge, the technical staff or maintenance officer of each educational building.

\subsection{Peeling Paint}

Peeling paint was the most common form of critical decay which was found on the façade of the buildings, especially on the plastered walls, ceilings, beams and columns. These components were consistently exposed to sunlight, rain, wind and dampness, resulting in peeling paint. The excessive exposure spoiled the paint surfaces and thus the surfaces had become chalky, flaked and blistered. Figure 1 shows the effect of peeling paint on the external walls and columns. The paint on the ceiling was also gradually being peeled off due to the presence of moisture. The peeled-off paint on the ceiling could be easily found on the top floors of the buildings because the rainwater had entered through the roof, as some of the roof tiles were missing or had been blown away by strong winds.
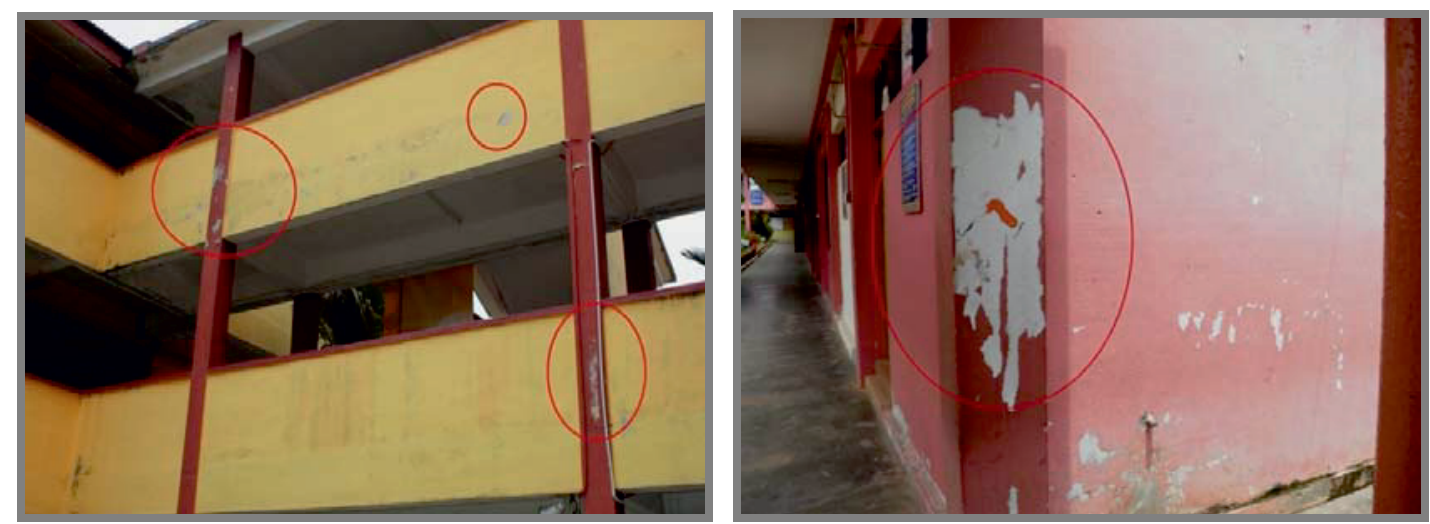

Figure 1. Peeling paint on external walls and columns

\subsection{Dampness}

Dampness in the educational buildings was the result of water incursion, either from internal sources or external sources. This decay became a serious problem when various materials in the educational buildings became wet for extended periods of time. Besides, excessive moisture in the air due to poor ventilation inside the buildings could have also led to dampness. The common type of dampness found in the educational buildings was penetrating damp. Dampness was found on the ceiling and walls due to the ingress of water.

The classrooms, especially those on the top floor, were greatly affected by dampness to the ceiling where the roof tiles were missing or had been blown away by the wind. The rainwater had penetrated directly into the building itself, resulting in dampness as shown in Figure 2. 

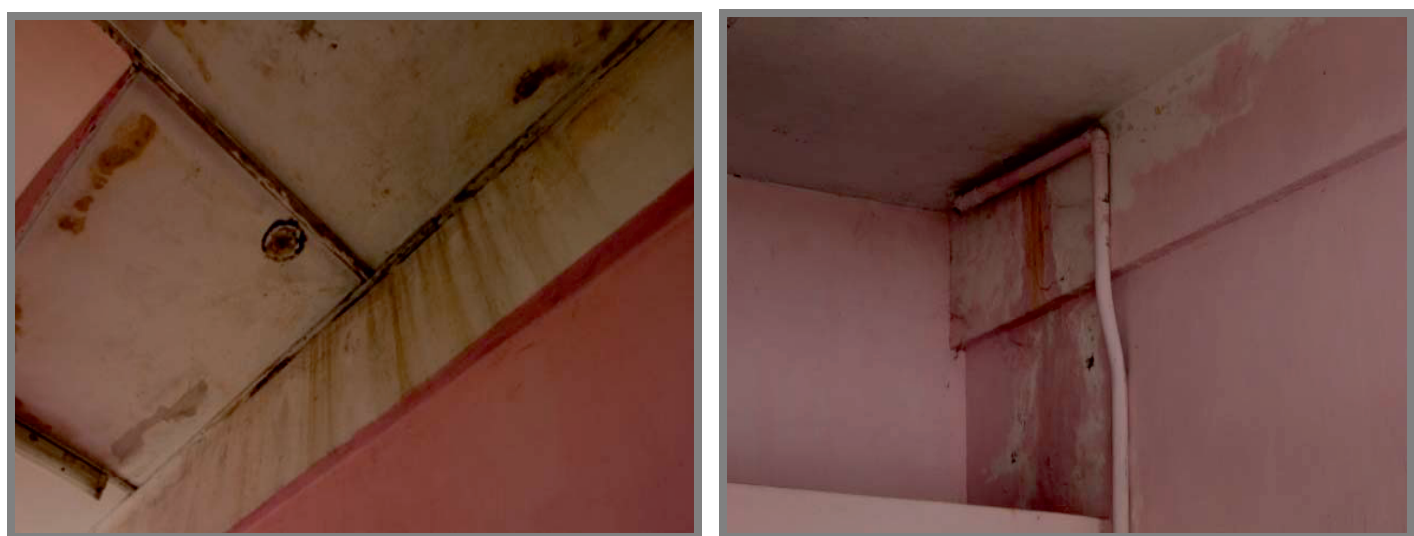

Figure 2. Penetrating damp on the ceiling (left) and damp caused by leaking pipe (right)

Besides, dampness can arise from unattended water caused by leaking pipes, gutters and flushes. The leaking water penetrated into the wall, resulting in horrible water stains. Over a prolonged period of dampness penetration and poor ventilation within the building, excessive moisture promoted the growth of mould on the surfaces of the walls.

The growth of mould and fungi is an ordinary consequence of excessive dampness. Mould and fungi will grow when they gain enough moisture and nutrients. However, the growth of mould caused a lot of problems to the educational building environment. It not only physically affected the appearance of the building structure, but also resulted in various health issues among the students and staff.

\subsection{Discoloration}

Discoloration of the paintwork was commonly found in the inspected educational buildings. The paintworks of the surfaces were either a brownish, blackish or yellowish colour. This decay is often related to the presence of dampness or biological attack. Moulds grow aggressively on the surface of paintworks when there is excessive moisture, resulting in discoloration.

A simple repainting will not solve the problem for long. Furthermore, serious discoloration will lead to structural damage and damage to the facade. Figure 3 shows a blackish discolouration of the paintwork.
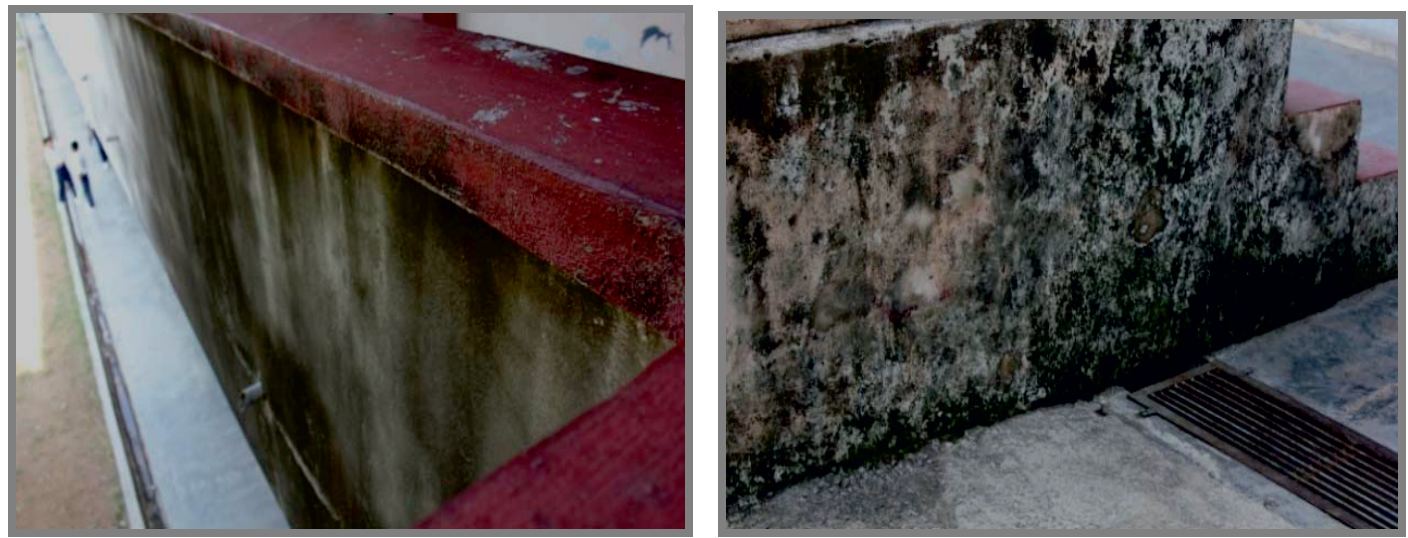

Figure 3. Blackish discoloration of paintwork 


\subsection{Timber Decay}

The problem of timber decay is mainly found on door frames, window frames, timber roof struts and ceiling battens. These components are exposed to moisture, which is the main critical element in the timber decay process, while some timber materials decay because of aging, e.g. ceiling battens. Figure 4 shows the timber door frames in the toilets which suffered the most deterioration because they were highly exposed to water. This type of timber decay is also known as wet rot. Wet rot is the most common type of timber decay in which the fungus feeds on the timber; the timber must be damp or wet enough for the fungus to thrive and continue the rotting process. Timber decay occurs if the timber becomes sufficiently wet, and oxygen and nutrients are present.
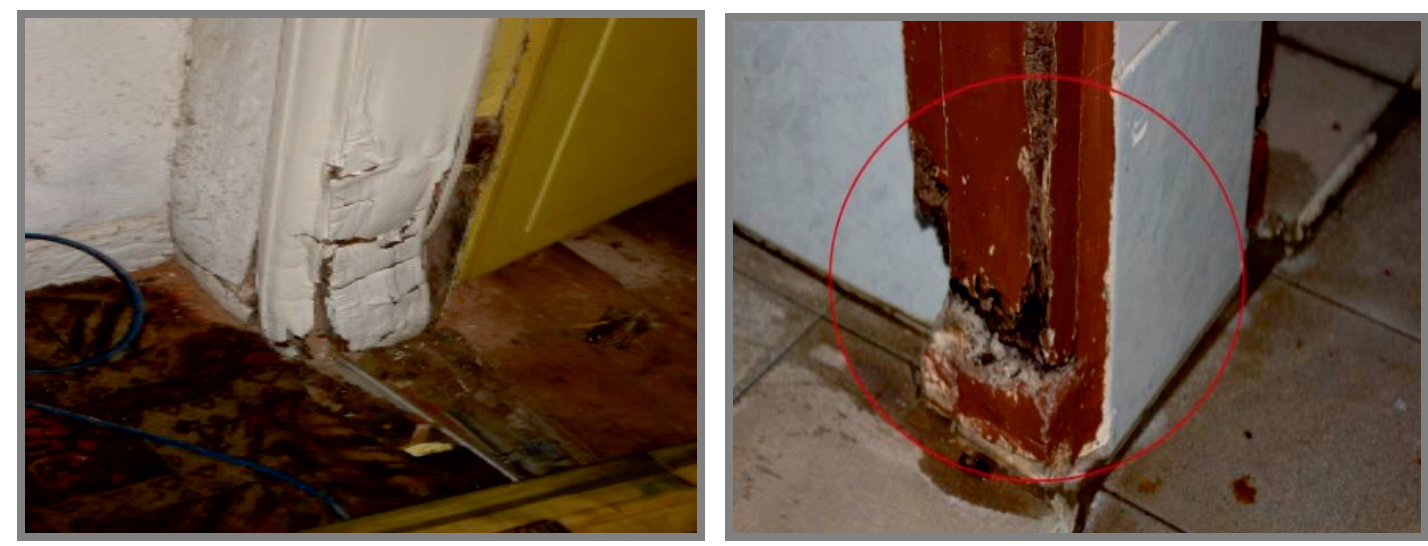

Figure 4. Timber decay on door frames at toilet area.

\subsection{Cracking}

Cracks occurred on the various elements in the educational buildings such as the walls, ceilings, beams, columns and even floors. Many structural and non-structural cracks were found. Structural cracks take place in walls, beams and columns. However, non-structural cracks usually happen in plaster or other finishes with cement rendering. Cracking can be classified into a few types: vertical, horizontal, diagonal and hairline. Figure 5 shows a horizontal crack in the beam. Some parts of the inspected buildings showed serious cracks while some only showed minor cracks.

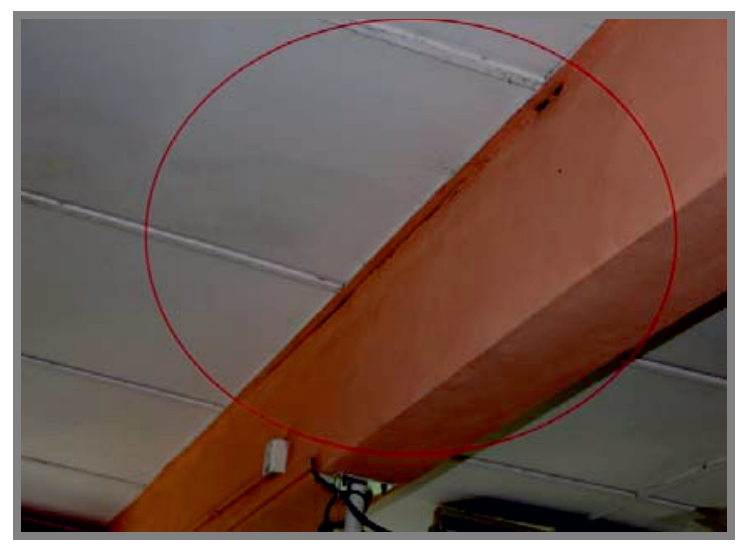

Figure 5. Horizontal crack on beam 


\subsection{Gap and Detachment}

Some visible gaps were found between the elements, such as the walls, columns, beams, ceilings, door frames, etc. Figure 6 illustrates a gap that had formed at the interface between the old beam and the new beam. In fact, a new building had been connected to the original building. However, this new addition was detached from the old building, resulting in a large and visible gap. A gap was also found between the wall and the door frames. The shrinkage and expansion of the door frames (timber materials) due to atmospheric conditions may have caused the gaps. Besides door frames, other timber materials such as ceiling battens were also found to have gaps from the wall. In such circumstances, dampness may penetrate into the building and result in water stains. Moreover, the detachment of columns from the wall was basically caused by poor construction and workmanship.

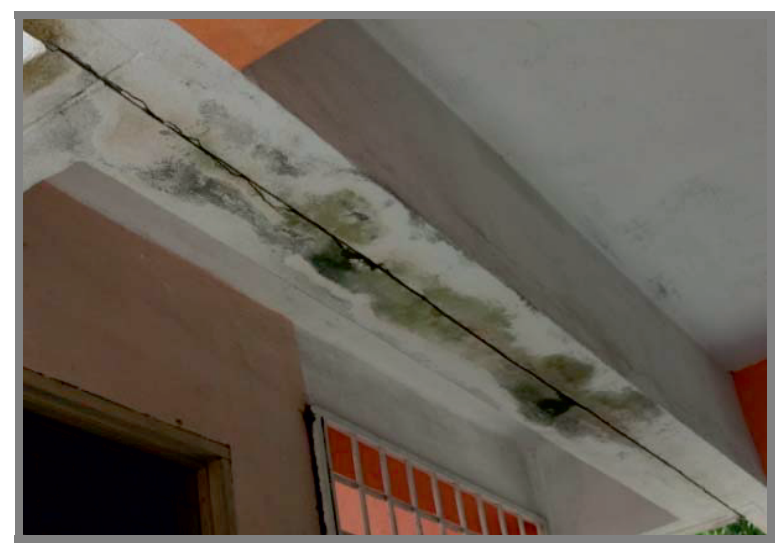

Figure 6: A visible gap between the beams.

\subsection{Defective Plaster Renderings}

Plaster rendering was the widest used finish in the educational buildings. Most of the sections in the inspected educational buildings were finished by plaster rendering. However, the plaster renderings underwent deterioration after a period of time. Some of the plaster renderings were decayed, uneven, broken and also cracked. Figure 7 shows the broken plaster renderings. Although plaster renderings tend to deteriorate as the building gets older, many damaged plaster renderings still appeared just after the construction, mainly due to poor workmanship or low quality material.

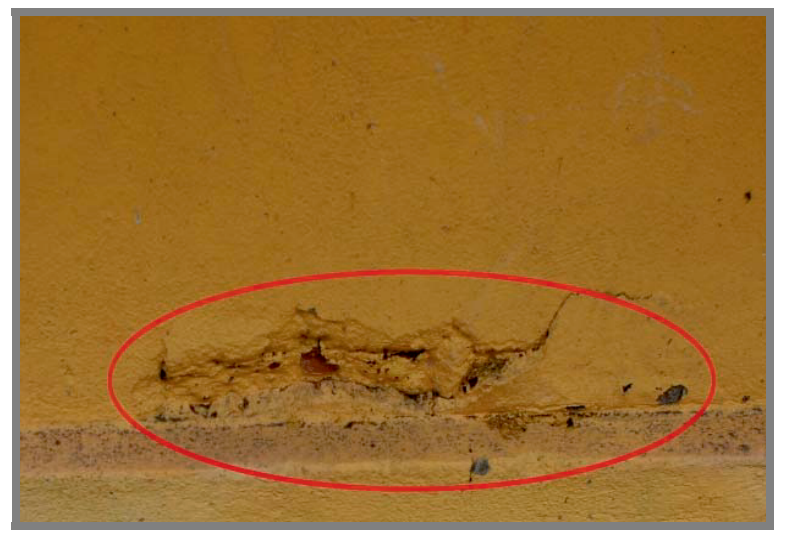

Figure 7. Broken plastered renderings 


\subsection{Termite Attack}

Timber deteriorates when it is exposed to water penetration and excess moisture. Termites attack damp and digestible timber. Large amounts of timber materials had been attacked by termites, causing the timber structures to become soft. These materials included timber doors, door frames, roof struts and window frames. Some of the furniture suffered from this decay as well. Figure 8 shows the effect of termite attack on the timber door.

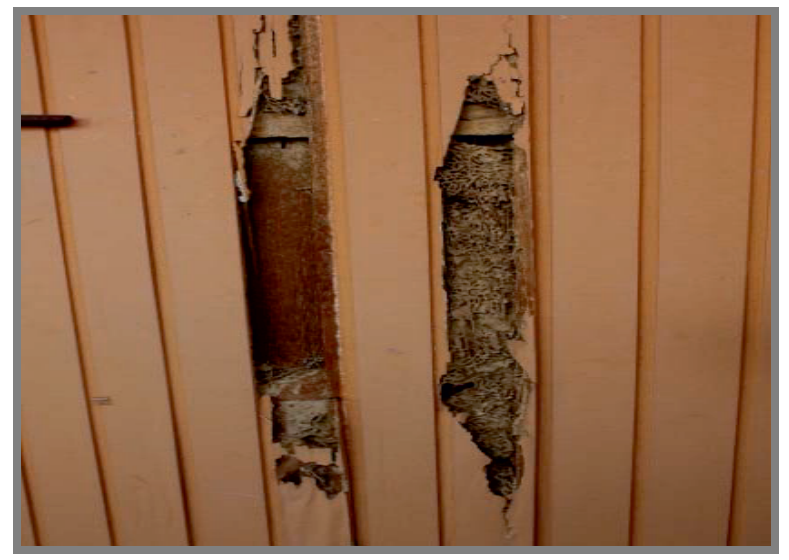

Figure 8. Termite attack on door

\subsection{Corrosion of Steel}

The steel materials used in the buildings, for example, the hinges, handrails and door handles, were corroded. Fundamentally, most steel materials corrode due to the outdoor atmosphere, which contains oxygen and moisture, the two critical elements in the corrosion process. Moreover, these components are frequently exposed to climate extremes, such as sunlight, rain and dampness, especially in a hot and humid country like Malaysia. Their strength and corrosion resistance decrease gradually under long term exposure. As a result, corrosion of steel takes place. Occasionally, this decay is also caused by poor maintenance and the use of low quality materials.

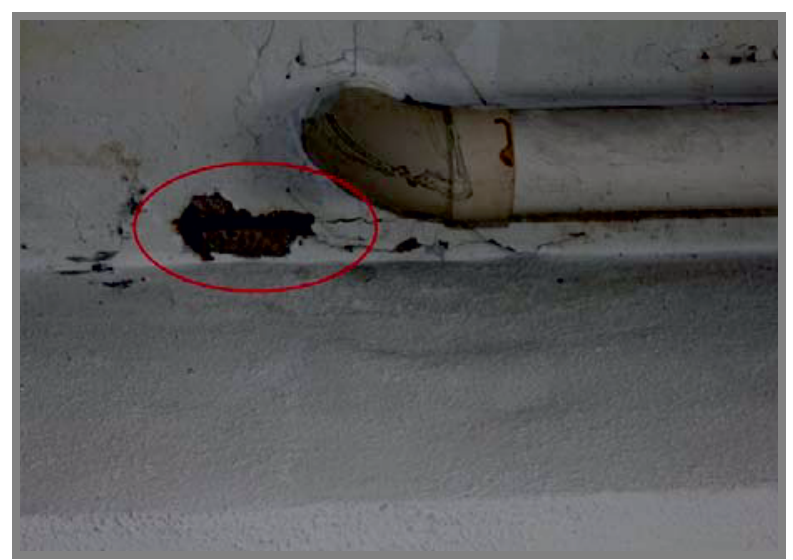

Figure 9. Spalling of concrete

In addition, spalling of concrete was found with its exposed reinforcement as shown in Figure 9. When the steel reinforcement eroded, the formation of rust caused a loss of bond between the steel and concrete, and this resulted in spalling. The integrity and performance of the structure can be influenced if this problem is not addressed instantly. 


\subsection{Defective Tiles}

Tiles were used as finishes to the walls and floors. The types of tiles used in the inspected educational buildings were ceramic tiles and homogenous tiles. There were only certain areas where the tiles were used as finishes because most of the areas were finished by plaster renderings which were cheaper. Those areas were the offices, cafeteria, computer labs, staff's toilets and multimedia hall. The major problems found in the inspected buildings were slippage, unaligned, cracked, broken and loose tiles. Tiles will crack and break when heavy objects are dropped on them. Figure 10 shows a mixture of tiles decay found in the buildings.
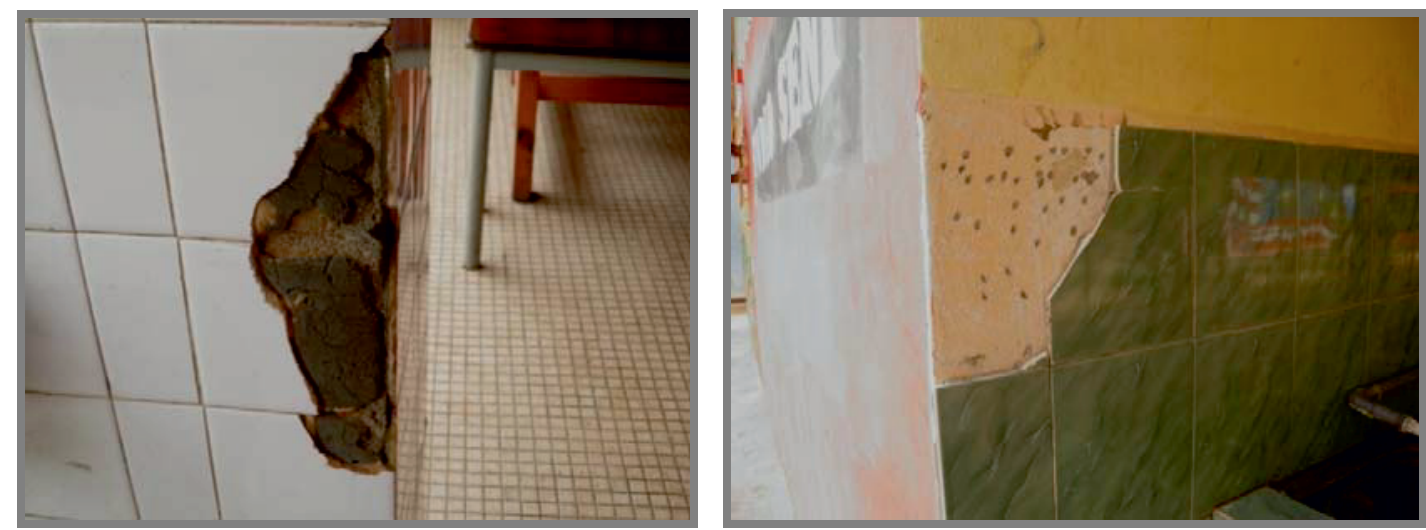

Figure 10. Defective tiles on walls

\subsection{Settlement}

Cracks on the lower parts of the structure indicated a crisis of settlement. The gap in the cracks was large, about $10 \mathrm{~mm}$, as shown in Figure 11. This may be associated with the movement of the ground beneath the foundations due to the weight of the building itself. Settlement occurs where a structure is founded on varying ground conditions or foundation failures. Other possible causes of this problem are soil erosion by flowing water, changes in ground water level, uneven bearing capacities of soils and poor soil conditions.

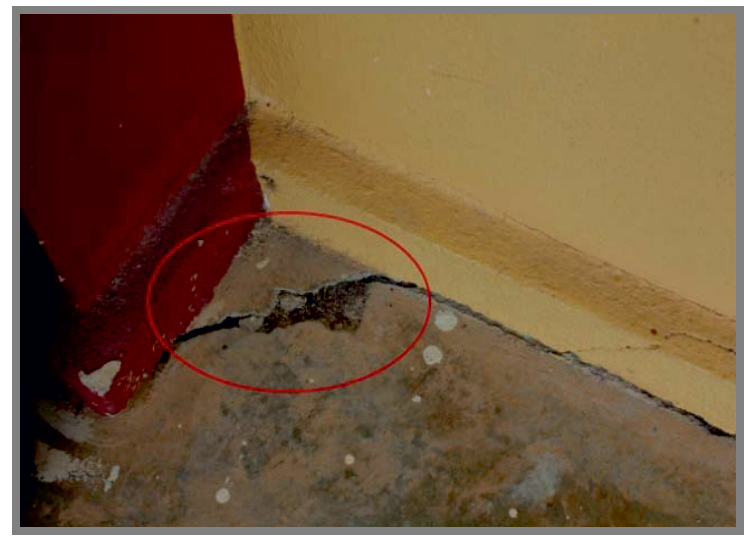

Figure 11. Cracks on the lower part of the building 


\section{Conclusions}

Educational buildings are widely exposed to all sorts of problems due to numerous factors. Decay and deterioration are critical as they can physically affect the appearance of a building as well as damage the building structure. This can subsequently affect the safety of the users of the building. Therefore, appropriate solutions to mitigate building decay and failures in educational buildings should be carried out in order to ensure that the buildings do not easily fall into decay. If the decay is not taken seriously, it may lead to structural failure. In brief, all parties such as the local government authorities, educational building authorities, consultants, contractors and the public, should be involved in remedial works and work together in order to diminish the occurrences of decay and failures in buildings. They should have a mutually close working partnership in order to form a strong and sustainable built environment for educational buildings.

\section{References}

1. A.G. Ahmad, Understanding Common Building Defects: The Dilapidation Survey Report. Universiti Sains Malaysia, Penang, 2004.

2. S.E. Ong, Building defects, warranties and project financing from pre-completion marketing, Journal of Property Finance, 8 (1) (1997) 35-51.

3. W.K. Chong, S.P. Low, Latent Building Defects: Causes and Design Strategies to Prevent Them. Journal of Performance of Constructed Facilities, 20 (3) (2006) 213-221.

4. P. Hii, Students in shock after school's walkway collapses. The Star, 20th April, 2011.

5. H. Mohd Isa, P.F. Hassan, M. Che Mat, Z. Isnin, Z. Sapeciay, Learning from Defects in Design and Build Hospital Projects in Malaysia, In International Conference on Social Science and Humanity, 5 (2011) 238-242.

6. M. Mahli, A.I. Che-Ani, M.Z. Abd-Razak, N.M. Tawil, H. Yahaya, School Age and Building Defects: Analysis Using Condition Survey Protocol (CSP) 1 Matrix, 2012.

7. M.S Aini, A. Fakhrul'l-Razi, M. Daud, N.M. Adam, R. Abdul Kadir, Analysis of Royal Inquiry Report on the collapse of a building in Kuala Lumpur: Implications for developing countries", Disaster Prevention and Management, 14 (1) (2005) 55-79.

8. N. Ahzahar, N.A. Karim, S.H. Hassan, J. Eman, A study of Contribution Factors to Building Failures and Defects in Construction Industry. Universiti Teknologi MARA, Pulau Pinang, 2011

9. O.A Lateef, M.F. Khamidi, A. Idrus, Sustainability in the Context of Maintenance: Building Defects in the Malaysia University Campuses. Universiti Teknologi PETRONAS, Malaysia, 2010

10. D.R. Bohnhoff, Investigating Building Failures. Unpublished thesis (PhD), University of Wisconsin-Madison, USA, 2001

11. A.L. Olanrewaju, Quantitative analysis of defects in university buildings: user prespective, Built Environment Project and Asses Management, 2 (2) (2012) 167-181.

12. T. Heitor, Potential Problems and Challenges in Defining International Design Principles for Schools, Evaluating Quality in Education Facilities, 2005, 44-54. 